\title{
ANALISA LAJU PERUBAHAN HARGA SAHAM LQ45 MENGGUNAKAN PERSAMAAN DIFERENSIAL
}

\author{
Zani Anjani Rafsanjani HSM ${ }^{1)}$ \\ 1) Program Studi Matematika, Fakultas Sains dan Teknologi Terapan, Universitas Ahmad \\ Dahlan \\ Banguntapan Bantul, Yogyakarta \\ 1) zani.anjani@math.uad.ac.id
}

Diterima: 31 Oktober 2020. Disetujui: 24 Desember 2020. Dipublikasikan: Desember 2020

\begin{abstract}
Abstrak
Pergerakan harga saham merupakan pembahasan yang sangat menarik dewasa ini. Perubahan harga yang dinamis setiap waktu membutuhkan analisa yang lebih mendalam untuk menentukan trend dan prediksi harga saham di masa yang akan datang. Sudah banyak metode yang digunakan untuk menganalisa dan memprediksi harga saham. Pada paper ini akan dilakukan analisa pada percepatan perubahan harga saham menggunakan pendekatan matematis yakni dengan menggunakan persamaan diferensial orde dua. Manfaat dari penelitian ini adalah untuk mendapatkan koefisien perubahan harga saham yang dapat digunakan untuk memprediksi harga saham pada waktu yang akan datang. Harga saham yang akan diamati adalah saham yang termasuk pada kategori LQ45. Selanjutnya, dilakukan analisa program dengan memanfaatkan software Matlab. Pada akhir penelitian, dihasilkan koefisien perubahan harga untuk sahamsaham LQ45 melalui data historis yang disediakan.
\end{abstract}

Kata kunci: Perubahan harga saham, persamaan diferensial, percepatan

\begin{abstract}
The stock price movement is a very interesting discussion today. Dynamic price changes every time requires deep analysis to determine trends and stock price predictions in the future. There have been many methods used to analyze and predict stock prices. This paper will analyze the acceleration of stock price changes using a mathematical approach, known as a second-order differential equation. The benefit of this research is to obtain a coefficient of change in stock prices that can be used to predict stock prices in the future. Stock prices that will be observed are stocks including the LQ45 category. Furthermore, program analysis is carried out using Matlab software. At the end of the study, the coefficient of price change for LQ45 stocks was generated through provided historical data.
\end{abstract}

Keywords: stock price changes, differential equation, acceleration

\section{PENDAhULUAN}

Saham merupakan sebuah penyertaan modal atas kepemilikan sebuah perusahaan (Andy, 2007). Penyertaan atas modal ini dilakukan untuk mendapatkan bagi hasil yang disepakati oleh kedua pihak dalam Rapat Umum Pemegang Saham (RUPS). Tidak ada persentase pasti dalam pembagian dividen sebuah saham. Akan tetapi besaran dividen ini bergantung pada penghasilan yang diperoleh perusahaan atas kinerja yang dilakukan. Pemegang saham pada pasar saham disebut sebagai investor.

Pada praktiknya harga saham sebuah perusahaan bergerak fluktuatif setiap waktu. Hal ini diakibatkan oleh adanya penawaran dan permintaan pada pasar keuangan. Pada kondisi harga saham naik, terjadi penawaran yang cukup tinggi dibandingkan permintaan. Sementara pada 
kondisi harga saham turun terjadi peningkatan permintaan. Fluktuasi harga saham ini mengakibatkan adanya kemungkinan-kemungkinan bahwa harga saham pada waktu yang akan datang (future time) lebih besar dari harga saham pada waktu sebelumnya. Namun ada juga kemungkinan bahwa harga saham pada masa yang akan datang (future time) lebih rendah dari harga saham pada waktu sebelumnya. Terlebih pada saat terjadi issue global yang mengakibatkan harga saham menjadi sangat tinggi maupun sangat rendah. Perubahan harga saham ini banyak dipelajari oleh Desi A. dan Asthohar (2012) atas return yang diperoleh. Lebih lanjut, selain itu menurut Sulia, (2017) mempelajari tentang factor-faktor penyebab perubahan harga saham dengan objek saham pada LQ45.

Untuk mengatasi dampak perubahan harga saham yang cukup signifikan, perlu dilakukan analisa dan prediksi harga saham. Tujuannya adalah untuk mendapatkan nilai investasi yang optimal dan menekan kerugian yang diperoleh akibat penurunan harga saham pada waktu-waktu tertentu. Umanto, (2008) melakukan analisa serta penilaian optimal kinerja suatu saham melalui return yang diperoleh dengan menggunakan pendekatan statistika sehingga diperoleh portofolio optimal yang menekan resiko. Selain itu, beberapa pendekatan secara matematis juga dilakukan dalam menganalisa perubahan harga saham. CFA, (2020) melakukan analisa dan prediksi harga saham menggunakan metode Neural Network dan Time series sebagai pendekatan yang sangat relevan saat ini.

Pada artikel ini dibahas mengenai percepatan perubahan harga saham dengan menggunakan pendekatan matematis yang lain. Perubahan harga saham dianalisis melalui return yang diperoleh menggunakan model perubahan yang memanfaatkan persamaan diferensial orde dua. (Zeithamer, 2010) membahas mengenai persamaan diferensial pada perubahan penurunan harga nilai barang dengan percepatan penurunan. Model persamaan diferensial tersebut diterapkan untuk menganalisa perubahan harga saham. Sehingga diperoleh trend perubahan penurunan harga saham dan koefisien penurunan harga saham.

Sistematika penulisan paper ini dibagi kedalam beberapa bab. Pada Bab 2 diberikan tinjauan pustaka terhadap konsep-konsep serta metode yang digunakan dalam artikel ini. Selanjutnya model persamaan diferensial orde dua untuk menganalisa perubahan harga saham dijelaskan pada Bab 3. Pada Bab 4 diberikan analisis data historis untuk saham-saham LQ45. Pada bab terakhir diberikan analisa dan penarikan kesimpulan terhadap model dan data yang diberikan.

\section{TINJAUAN PUSTAKA}

\subsection{Persamaan Penurunan Harga Relatif}

Pada bidang ekonomi perubahan harga barang dapat dinyatakan sebagai selisih harga barang antara harga saat ini dengan harga mula-mula. Secara matematis perubahan harga ini dapat dinyatakan pada Persamaan (1) berikut

Keterangan

$$
D(t)=P(t)-P\left(t_{0}\right)
$$

$S(t)=$ Selisih harga pada waktu $t$

$P(t)=$ Harga barang pada waktu $t$

$P\left(t_{0}\right)=$ Harga barang awal.

Melalui selisih harga ini, dapat ditentukan pula perubahan harga relative. Persamaan perubahan relative dapat ditemukan di (Zeithamer, 2010), (Zeithamer,2012), (Zeithamer, 2013) dan (Zani, Farikhin, Siti, 2015). Perubahan harga relative dapat dinyatakan sebagai proporsi antara selisih harga dengan harga barang pada saat mula-mula yang dapat dinyatakan oleh Persamaan (2) yaitu

$$
\widehat{D}(t)=\frac{D(t)}{P\left(t_{0}\right)}=\frac{P(t)-P\left(t_{0}\right)}{P\left(t_{0}\right)} .
$$

Pada (1) dan (2) dapat dinyatakan sebagai perubahan harga barang dan perubahan harga barang relative secara umum. Sehingga dapat diterapkan pada berbagai bidang ekonomi seperti halnya harga komoditas hingga harga saham. 
Sementara untuk perubahan harga saham dan perubahan harga saham relative dapat dinyatakanoleh Persamaan (3) dan (4) secara berturut-turut yakni

$$
\begin{aligned}
& D_{s}(t)=S(t)-S\left(t_{0}\right), \\
& \widehat{D}_{S}(t)=\frac{S(t)-S\left(t_{0}\right)}{S\left(t_{0}\right)} .
\end{aligned}
$$

\subsection{Persamaan Diferensial}

Persamaan diferensial merupakan sebuah persamaan matematis yang memuat ekspresiekspresi turunan dari satu atau lebih variable tak bebas yang berkaitan dengan satu atau lebih variable bebas. Apabila variable yang terlibat hanya satu variable bebas maka persamaan tersebut dinamakan sebagai Persamaan Diferensial Biasa (Dennis \& Michael, 2009). Sebagai contoh yakni pada Persamaan (5)

$$
\frac{d y}{d x}+4 x y=2 e^{2 x}
$$

Sementara bila persamaan memuat dua atau lebih variable, maka persamaan disebut dengan Persamaan Diferensial Parsial (Dennis \& Michael, 2009). Contoh Persamaan Diferensial Parsial dapat dilihat pada Persamaan (6)

$$
\frac{\partial^{2} u}{\partial x^{2}}=\frac{\partial u}{\partial v}
$$

Secara umum persamaan diferensial linier orde dua dapat dituliskan pada Persamaan (7) berikut ini (Shapley, 2004)

$$
a_{0}(x) \frac{d^{n} y}{d x^{n}}+a_{1}(x) \frac{d^{n-1} y}{d x^{n-1}}+\cdots+a_{n}(x) y=b(x),
$$

dengan $a_{0}$ tidak sama dengan nol.

Persamaan (7) dapat dibedakan menjadi dua jenis yakni persamaan diferensial linier orde dua homogen yakni jika $b(x)=0$ dan non-homogen jika $b(x) \neq 0$. Sedangkan persamaan diferensial (7) dapat dinyatakan sebagai persamaan diferensial non-linier bila variable tak bebas pada ruas kanan memiliki orde lebih dari satu (Shapley, 2004).

\section{METODE PENELITIAN}

Pada penelitian ini dilakukan dilakukan studi literature terhadap pasar modal dan juga harga saham yang terlibat pada pasar modal Indonesia. Selanjutnya dipelajari juga teori yang membahas mengenai return yang diperoleh dari perdagangan saham. Selain itu juga dipelajari resiko resiko pasar saham. Setelah mempelajari resiko pasar saham, dilakukan study terhadap analisa perubahan harga saham untuk mengetahui trend dan prediksi masa depan harga saham.

Pendekatan matematis pada perubahan harga saham juga dilakukan dengan menggunakan model matematika persamaan diferensial orde dua. Dibangun sebuah persamaan diferensial linier orde dua yang dapat diaplikasikan pada permasalahan perubahan harga saham. Model ini digunakan untuk mengetahui laju perubahan harga saham pada interval waktu tertentu.sehingga dapat diperoleh koefisien laju perubahan.

Tahap selanjutnya, diambil data primer harga saham yang temasuk pada daftar LQ45. Selanjutnya data primer tersebut diujikan kepada model yang telah dibentuk menggunakan software Matlab. Lebih lanjut dapat ditarik kesimpulan dari hasil uji komputasi Matlab. 


\section{PEMBAHASAN}

Saham merupakan salah satu instrument keuangan yang cukup diminati karena sejumlah keuntungan yang dapat diperoleh. Namun, pergerakan harga saham cukup flutuatif setiap waktu. Perubahan ini dapat dinyatakan sebagai perpindahan harga dinamik dari waktu satu ke waktu yang lain.

Perubahan harga saham dapat dinyatakan secara matematik menggunakan (3). Sedangkan untuk laju perubahan harga saham pada waktu $t$ dapat dinyatakan dengan menggunakan ekspesi matematik berupa persamaan diferensial linier pada Persamaan (8) sebagai

$$
\frac{d D_{s}(t)}{d t}
$$

Proses perubahan harga saham pada waktu $t$ dapat di tuliskan sebagai percepatan perubahan harga saham yang dinyatakan dengan persamaan diferensial linier orde dua. Persamaan tersebut dituangkan pada Persamaan (9) berikut

$$
\frac{d^{2} D_{S}(t)}{d t^{2}}+\frac{1}{\theta} \frac{d D_{S}(t)}{d t}=0
$$

Keterangan

$D_{s}(t)=$ Perubahan harga saham pada waktu $t$

$\theta \quad=$ koefisien laju perubahan harga saham.

Diasumsikan bahwa $\theta>0$ serta diberikan syarat awal $D_{S}(0)=D_{0}$ dan $\frac{d D_{S}(0)}{d t}=v_{0}$ dan nilai $v_{0}>0$.

Persamaan (9) dapat diselesaikan dengan menggunakan metode akar karakteristik penyelesaian persamaan diferensial dengan menggunakan syarat awal yang telah diberikan. Solusi dari (9) dinyatakan pada Persamaan (10) yang dituliskan sebagai

$$
D_{S}(t)=D_{0}+\left(1-e^{\frac{t-t_{0}}{\theta}}\right) \theta v_{0}
$$

Berdasarkan pada model yang dihasilkan pada (9) dilakukan analisis data historis pada saham-saham LQ45. Data diperoleh dari Investing.com dengan mengambil data historis harga saham pada bulan Agustus hingga Oktober 2020. Dari analisa data menggunakan software Matlab, diperoleh koefisien laju perubahan harga saham untuk saham-saham pada LQ45 pada Tabel 1 berikut.

Tabel 1. Koefisien laju perubahan harga saham

\begin{tabular}{|c|c|c|}
\hline Nama Saham & $D_{0}$ & $\theta$ \\
\hline ADHI & -0.01709 & 0.00862 \\
\hline ADRO & 0.00893 & 0.01747 \\
\hline ANTM & 0.03286 & 0.0281 \\
\hline ASII & 0.01409 & 0.0095 \\
\hline BBCA & 0.01042 & 0.0053 \\
\hline
\end{tabular}

Berdasarkan pada Tabel 1, dapat diketahui bahwa laju perubahan harga saham PT AHDI pada waktu $t$ sebesar $0.86 \%$. Sementara laju perubahan PT ADRO sebesar 1.75\%. Laju perubahan harga saham PT Aneka Tambang pada waktu $t$ sebesar $2.81 \%$. PT ASII memiliki laju perubahan harga saham sebesar $0.95 \%$ dan PT Bank BCA memiliki laju perubahan harga saham sebesar $0.53 \%$

Berikut ini disajikan grafik hasil analisa laju perubahan harga lima saham LQ45 pada Gambar 1 - Gambar 5. 


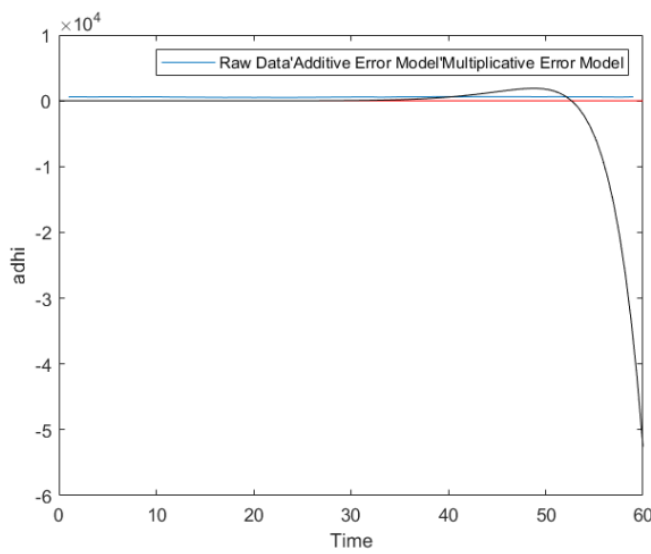

Gambar 1. Grafik laju perubahan harga saham ADHI

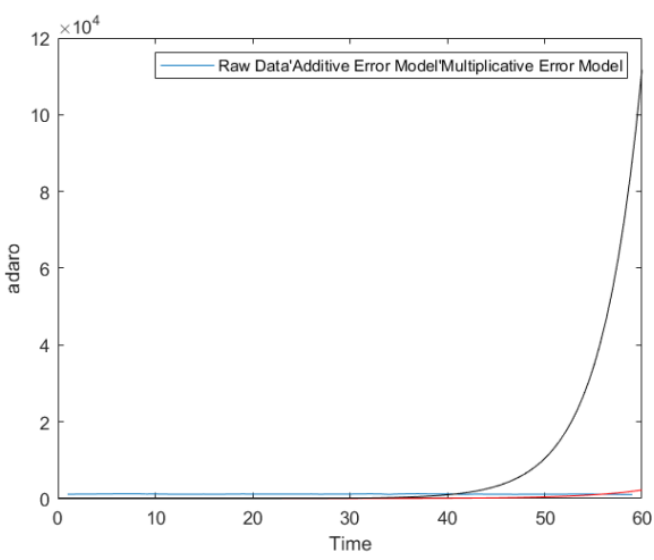

Gambar 2. Grafik Laju perubahan harga saham ADRO

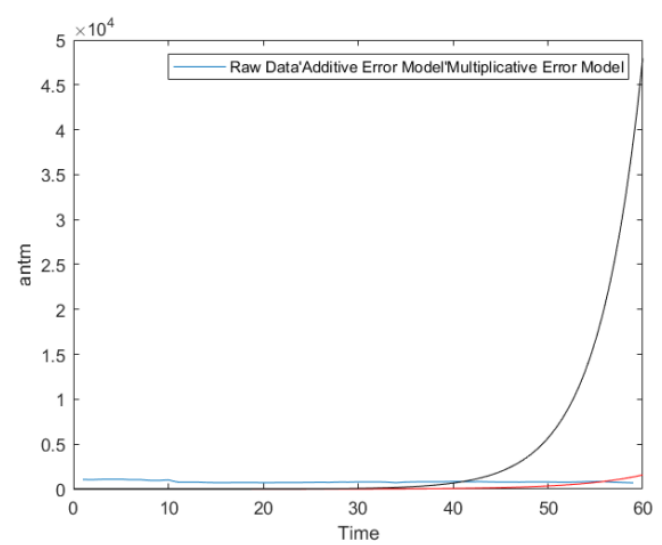

Gambar 3. Grafik laju perubahan harga saham ANTM

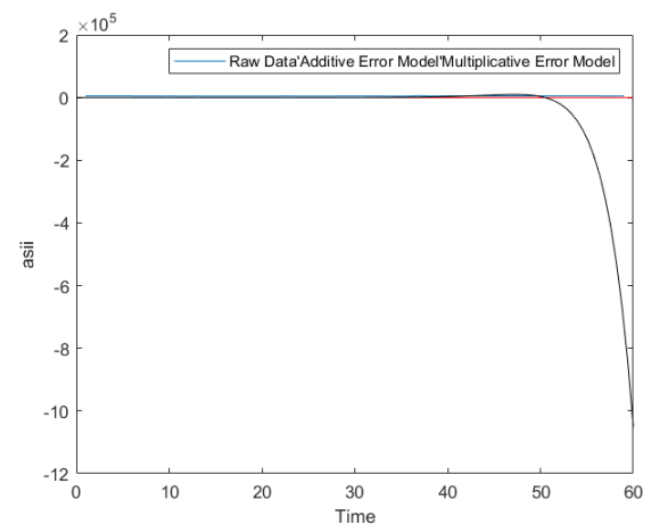

Gambar 4. Grafik laju perubahan harga saham ASII

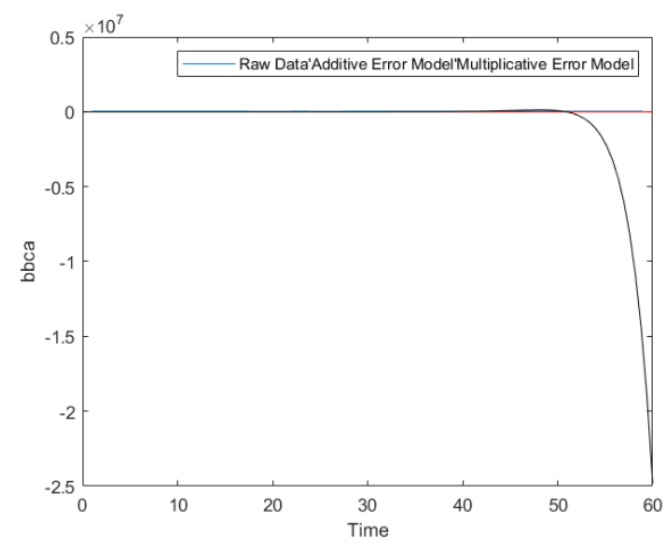

Gambar 5. Grafik laju perubahan harga saham BBCA

Berdasarkan pada data historis masing-masing saham, dapat dilihat bahwa laju perubahan harga saham pada bulan Agustus hingga Otober tidak melebihi 3\%. Hal ini menunjukkan bahwa tidak terjadi perubahan harga yang cukup signifikan selama 3 bulan terakhir. Artinya 
bahwa tidak ada kerugian yang terlalu besar maupun keuntungan yang cukup signifikan selama periode transaksi Agustus-Oktober.

Trend laju perubahan harga saham pada masing-masing perusahaan menunjukkan bahwa laju perubahan harga saham mengikuti pola eksponensial yang asimtotik pada nilai nol. Artinya bahwa laju perubahan harga saham tidak mengalami perubahan yang cukup signifikan dengan nilai laju perubahan yang berada tidak jauh pada garis nol.

\section{KESIMPULAN}

Pada penelitian ini, dilakukan analisa pada laju percepatan perubahan harga saham yang termasuk pada saham kategori LQ45. Untuk menganalisa laju perubahan harga saham tersebut, dapat digunakan pendekatan matematis menggunakan persamaan diferensial linier orde dua. Pada analisa yang dilakukan menggunakan persamaan diferensial linier orde dua, dapat diperoleh nilai laju perubahan harga saham untuk lima ojek saham. Dari kelima saham tersebut menunjukkan bahwa laju percepatan perubahan harga saham yang dialami oleh saham LQ45 tidak signifikan. Artinya tidak ada perubahan harga yang cukup besar pada bulan Agustus hingga Oktober. Dilihat dari trend yang dihasilkan, laju percepatan perubahan harga saham mengikuti pola eksponensial selama tiga bulan terakhir.

\section{DAFTAR PUSTAKA}

Andy P. T. (2007). Menilai Harga Wajar Saham (Stock Valuation). (pp.1-2). Jakarta: PT. Alex Gramedia Computindo.

CFA Institute. (2020). Ethical and Professional Standards, Quantitative Methods, and Economics. New York: Wiley.

Dennis, G. Z. \& Michael, R. C. (2009). Differential Equations: With Boundary-Value Problem Seventh Edition, USA: Brooks/Cole.

Desy A. dan Astohar. (2012). Analisis Faktor-Faktor Yang Mempengaruhi Return Saham. Jurnal Ilmu Manajemen dan Akuntansi Terapan. 3(1). 1-15. http://jurnal.stietotalwin.ac.id/index.php/jimat/article/view/29

Sulia. (2017). Analisis Faktor-Faktor yang Mempengaruhi Harga Saham Pada Perusahaan LQ45 Yang Terdaftar di Bursa Efek Indonesia. Jurnal Wira Ekonomi Mikroskil. 7(2). 130. https://www.mikroskil.ac.id/ejurnal/index.php/jwem/article/view/470

Umanto E. (2008). Analisis dan Penilaian Kinerja Portofolio Optimal Saham-Saham LQ45. Bisnis dan Birokrasi: Jurnal Ilmu Administrasy dan Organisasi. 15(3). 178-187. http://journal.ui.ac.id/index.php/jbb/article/viewArticle/562

Shepley L. R. (2004). Differential Equation $3^{\text {rd }}$ Edition. (pp. 3-5). India: Wiley.

Zeithamer T. (2010). A Deterministic Differential Equation for the Fall ini Market Value of Goods with Acceleration. EuMotion. 10(1) 1-7.

Zeithamer T. (2012). Economic Phenomena on the View Point of the Mechanics of Material. Procedia-Social and Behavioural Science. 55. 547-553. https://www.sciencedirect.com/science/article/pii/S1877042812039973

Zeithamer T. (2013). Possible Use of Deterministic Equation of Motion in Commodity Price Theory and for Training Appraisers. Procedia Social and Behavioral Science. 106. 2063-2070.

https://www.sciencedirect.com/science/article/pii/S1877042813048581/pdf?md5=3f083e 0e3668638fb53fb85d8553939b\&pid=1-s2.0-S1877042813048581-main.pdf

Zani A. R., Farikhin Siti K. (2015). Estimasi Parameter Dalam Model Depresiasi Harga Untuk Komoditi Kakao dan Mobil. Prosiding SNMPN UNDIP. -. 65-69. http://eprints.undip.ac.id/47612/ 


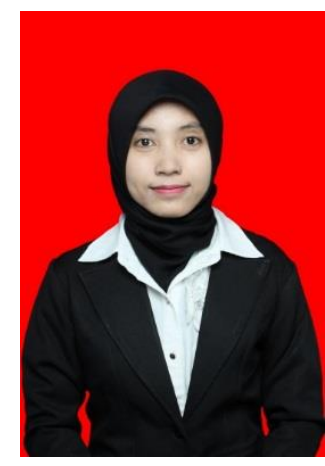

\section{Biodata Penulis}

Zani Anjani Rafsanjani HSM, S.Si., M.Sc., lahir di Semarang pada tanggal 6 Maret 1994. Penulis menempuh pendidikan S1 di Program Studi Matematika Universitas Diponegoro, Kota Semarang Indonesia pada tahun 2011-2015. Kemudian melanjutkan studi pascasarjana di Universitas Gadjah Mada, Kota Yogyakarta Indonesia di Program Studi Matematika pada tahun 2015-2018.

Saat ini penulis bekerja sebagai Dosen di Universitas Ahmad Dahlan Yogyakarta Indonesia sebagai Dosen di Program Studi Matematika, Fakultas Sains dan Teknologi Terapan (FAST). Selain itu penulis juga menjabat sebagai Penjamin Mutu di Universitas Ahmad Dahlan. Hingga sat ini, penulis aktif dalam melakukan penelitian dan menulis artikel ilmiah di bidang matematika dan terapannya. 